\title{
Effect of Early Mobilization from Bed to Wheel Chair on Regional Ventilation Distribution Assessed by Electrical Impedance Tomography in Respiratory Failure Patients
}

\section{Siyi Yuan}

Peking Union Medical College Hospital

Huaiwu He

Peking Union Medical College Hospital

Yun Long ( $D$ iculong_yun@163.com )

Peking Union Medical College Hospital https://orcid.org/0000-0002-9196-4651

Yi Chi

Peking Union Medical College Hospital

\section{Zhanqi Zhao}

Fourth Military Medical University

\section{Research}

Keywords: Electrical impedance tomography, Reginal lung ventilation, Early mobilization

Posted Date: August 20th, 2020

DOI: https://doi.org/10.21203/rs.3.rs-60116/v1

License: (c) (1) This work is licensed under a Creative Commons Attribution 4.0 International License.

Read Full License 


\section{Abstract}

Backgrounds: There was limited knowledge about the effect of early mobilization on regional lung ventilation in patients with respiratory failure. The aim of the study was to examine whether electrical impedance tomography (EIT) could help to predict the improvement in ventilation distribution due to mobilization.

Methods: Forty-one patients with respiratory failure, who had weaned from ventilator and received early mobilization were prospectively enrolled in this study. EIT was used to assess regional lung ventilation distributions at 4 timepoints during the early mobilization from bed to wheelchair ( $T_{\text {base }}$ : baseline, supine position at the bed, $T_{30 \mathrm{~min}}$ : sitting position on the wheelchair after $30 \mathrm{~min}, \mathrm{~T}_{60 \mathrm{~min}}$ : sitting position on the wheelchair after $60 \mathrm{~min}, \mathrm{~T}_{\text {return }}$ : return to supine position on the bed after early mobilization). The EITbased global inhomogeneity ( $\mathrm{GI}$ ) and center of ventilation (CoV) indices were calculated. EIT images were equally divided into four ventral-to-dorsal horizontal regions of interest (ROls 1-4). Depending on the improvement of ventilation distribution in dependent regions at $\mathrm{T}_{60 \mathrm{~min}}$ (threshold set to $15 \%$ ), patients were divided into recruited (DR) and non-recruited (Non-DR) groups.

Results: From the bed to the wheelchair, a significant and continuous increase of dependent regional ventilation distribution (ROI 3+4: baseline vs. $T_{30 \mathrm{~min}}$, vs. $T_{60 \mathrm{~min}}: 45.9 \pm 12.1$ vs. $48.7 \pm 11.6$ vs. $49.9 \pm 12.6$, $p=0.015)$ and COV (COV baseline vs. $T_{30 \mathrm{~min}}$, vs. $\mathrm{T}_{60 \mathrm{~min}}: 48.2 \pm 10.1$ vs. $50.1 \pm 9.2$ vs. $50.5 \pm 9.6, p=0.003$ ). Besides, there was a significant decrease of $\mathrm{Gl}_{\text {at }} \mathrm{T}_{60 \mathrm{~min}}$. Patients in the DR group $(\mathrm{n}=18)$ had significantly higher oxygenation than the Non-DR group $(n=23)$ after early mobilization. ROI4 ${ }_{\text {Tbase }}$ was significantly negatively correlated to $\Delta \mathrm{SpO}_{2}(\mathrm{R}=0.72, p \rrbracket 0.001)$. Using a cut-off value of $6.5 \%, \mathrm{ROI}_{\text {Tbase }}$ had a $79.2 \%$ specificity and $58.8 \%$ sensitivity to predict response of dependent region recruitment due to early mobilization. The corresponding area under curve was $0.806(95 \% \mathrm{Cl}, 0.677-0.936)$.

Conclusions: EIT may be a promising tool to predict the ventilation improvement resulted from early mobilization.

Trial registration: Effect of Early Mobilization on Regional Lung Ventilation Assessed by EIT, NCT04081129. Registered 9 June 2019 - Retrospectively registered,

https://register.clinicaltrials.gov/prs/app/action/SelectProtocol? sid=S00096WT\&selectaction=Edit\&uid=U00020D9\&ts=2\&cx=v2cwij

\section{Background}

ICU patients are recommended to receive protocolized rehabilitation and early mobilization [1]. Early mobilization has been proved to prevent ICU acquired weakness and decrease duration of delirium [2-5]. Some research reported that early mobilization can increase ventilator-free days and prevent postoperative respiratory complications [6-8]. However, other study reported early mobilization did not 
show an expected outcome of decreasing mechanical ventilation days [9-11]. Considering the human resources, it is controversial whether all patients with mechanical ventilation need early mobilization. A part from improvements in strength and functional status, to promote the recovery of lung function is also a main purpose of early mobilization. On one hand, early mobilization can induce body position changing so as to influence the movement of diaphragm [12]. On the other hand, it is still not clear whether early mobilization can really promote lung recruitment in dependent area or not.

Electrical impedance tomography (EIT) is a noninvasive, non-ionizing monitoring system, which can obtain real-time imaging of regional lung ventilation at bedside by monitoring electrical impedance changes of the underlying tissue [13, 14]. EIT has already been used in Positive End Expiratory Pressure(PEEP) titration of acute respiratory distress syndrome (ARDS) patients $[15,16]$. To our best knowledge, no one has investigated the change of regional lung ventilation during the process of early mobilization. The aim of the study was to examine whether EIT could identify the impact of early mobilization on pulmonary ventilation distribution, and screen out those patients who benefit more from early mobilization, in line with individualized treatment.

\section{Patients And Methods}

\section{Patients}

This study for human subjects was approved by The Institutional Research and Ethics Committee of the Peking Union Medical College Hospital (JS-1896). Written informed consent was obtained from all patients before enrollment.

Adult critically ill patients with respiratory failure who received early mobilization were enrolled in this study. Inclusion criteria were the following: (1) presentation of respiratory failure-Partial pressure of oxygen/Fraction of inspiration oxygen $\left(\mathrm{PaO}_{2} / \mathrm{FiO}_{2}\right) \varangle 300$, oxygen saturation $\left(\mathrm{SpO}_{2}\right)<92 \%$, or respiration rate $(\mathrm{RR})>25 \mathrm{bpm}$. (2) Weaned from mechanical ventilation $₫ 24 \mathrm{~h}$. (3) need to carry out early mobilization according to patient's condition (e.g. ICU duration $\geq 1$ week, high risk of respiratory complication). Patients were excluded from the study if they were aged $<18$ years, were pregnant, had a body mass index (BMI) over $50 \mathrm{~kg} / \mathrm{m}^{2}$, had ribcage malformation, had any contraindication against using EIT monitoring (automatic implantable cardioverter defibrillator, chest skin injury, etc.), or had any contraindication

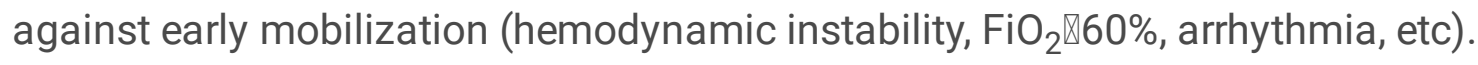

\section{Physiological measurements}

We collected baseline data at enrollment, including age, sex, ICU duration, days of intubation, type of surgery. Respiratory parameters like $\mathrm{RR}, \mathrm{SpO}_{2}, \mathrm{FiO}_{2}$, Tidal volume, and hemodynamic parameters, including heart rate (HR), mean arterial pressure (MAP) were obtained at different time points. 


\section{Experimental protocol}

Participants went through early mobilization as sitting on the wheel chair. The patient's condition before early mobilization was defined as baseline, with supine position on the bed. Then patients were moved from bed to wheelchair and sitting for 1 hour. After that, patients will return to supine position on the bed. During this movement, patients had EIT belt fixed on their chest and monitoring regional lung ventilation at 4 time points ( $T_{\text {base }}$ : baseline, supine position before early mobilization, $T_{30 \mathrm{~min}}$ : sitting position on the wheelchair for $30 \mathrm{~min}, \mathrm{~T}_{60 \mathrm{~min}}$ : sitting position on the wheelchair for $60 \mathrm{~min}, \mathrm{~T}_{\text {return }}$ : return to supine position on the bed after early mobilization.) Moreover, patients were spontaneous breathing with fixed $\mathrm{FiO}_{2}$ during the procedure.

\section{EIT measurements}

EIT measurements were performed with PulmoVista500 (Dräger Medical, Lübeck, Germany). During the protocol, a silicone EIT belt with 16 electrodes were attached on the surface of patient's chest in one transverse plane corresponding to the 4th intercostal parasternal space and was then connected to the EIT monitor for bedside visualization. At different positions, we make sure the 16-electrode array was attached to the same level on the chest surface, so that the lung ventilation is comparable. EIT evaluates lung ventilation by collecting potential differences and the known excitation currents in a $32 \star 32$ pixel matrix [17]. Each scan pixel demonstrates the instantaneous relative local impedance change compared with a reference state of local impedance. The stimulation frequency and amplitude were adjusted automatically by the EIT device to minimize the influence of background noise. EIT measurements were continuously performed at $20 \mathrm{~Hz}$. In addition, the data were digitally filtered using a low-pass filter with a cutoff frequency of $0.67 \mathrm{~Hz}$ to eliminate cardiac-related impedance changes. EIT data were analyzed by offline computer program.

\section{Analysis of EIT data}

The EIT data of 2 minutes at baseline and under different time points were acquired. Tidal images were calculated as the difference images between end-inspiration and end-expiration. An average of 2-min tidal images was calculated at each position to minimize the influence of spontaneous breathing. Mean tidal images were divided into four symmetrical, non-overlapping ventral-to-dorsal horizontal regions of interest (ROIs), ranging from the gravity-independent area to the gravity-dependent area, namely, the ventral (ROI1), mid-ventral (ROI2), mid-dorsal (ROI3) and dorsal (ROI4) regions.

The global inhomogeneity $(\mathrm{Gl})$ index can indicate the overall change in inhomogeneity of ventilation and the status of local lung distribution [18]. In brief, the sum of differences between individual pixels to average value was calculated. This sum value was normalized to the amplitude of impedance tidal variation. A lower $\mathrm{Gl}$ index value is related to a better ventilation homogeneity. 
The center of ventilation (CoV) describes the weighted geometrical center of the ventilation distribution [19-21]. When most of the tidal ventilation distributes to the dependent lung region, this results in a higher CoV value.

Patients were divided into two groups: (1) Dependent region recruited group(DR group): ventilation distribution of $\triangle \mathrm{ROI}(3+4) / \mathrm{ROI}(3+4)_{\text {Tbaseline }} \geq 15 \%$, (2) Dependent region not-recruitment group(Non-DR group): ventilation distribution $\Delta \mathrm{ROI}(3+4) / \mathrm{ROI}(3+4)_{\text {Tbaseline }^{\Delta}} 15 \%,\left(\Delta \mathrm{ROI}(3+4)=\mathrm{ROI}(3+4)_{\mathrm{T} 60 \mathrm{~min}^{-}}{ }^{-}\right.$ $\left.\mathrm{ROI}(3+4)_{\text {Tbaseline }}\right)$

\section{Statistical analysis}

Statistical analysis was measured with SPSS 23.0 (IBM, Armonk, NY) and Prism 7 (GraphPad Software, San Diego, California, USA).

Normal distribution was assessed with Kolmogorov-Smirnov normality test. Normally distributed results are presented as mean \pm SD whereas non-normally distributed results are presented as median (25th75th percentile). The Mann-Whitney test was used for comparisons of groups (recruitment group VS notrecruitment group). Comparisons of the trends of the related parameters according to the different positions were performed using a General Linear Model Repeated Measures (GLMRM)[22]. This model is an extension of the classical ANOVA, which allows handling both fixed effect (different position) and random effect (patient). GLMRM takes into account the correlation between multiple measurements on one patient and thus the estimated marginal means were adjusted for the covariates and the trends of related EIT parameters corresponding to the different position. When Mauchly's test of sphericity is not demanded ( $p<0.05)$, Epsilon (Greenhouse-Geisser) was used for the corrected test. All statistics were twotailed, and a $p$ value of less than 0.05 was considered to be significant.

\section{Results}

From Jan 2019 to Jan 2020, this study has enrolled 41 patients. The main characteristics of the patients are summarized in Table 1. The mean patient age was $64.3 \pm 14.1$, and 33/41(80\%) were men. 9/41(22\%) of patients had tracheotomy. The mean days of ICU duration was $14.3 \pm 13.3$. 
Table 1

Main characteristics of the study population

\begin{tabular}{|ll|}
\hline Characteristics & Data \\
\hline Age, years & $64.3 \pm 14.1$ \\
\hline Male sex,n(\%) & $33(80.5)$ \\
\hline BMI, $\mathbf{k g} / \mathbf{m}^{2}$ & $21.3 \pm 3.7$ \\
\hline APACHE-II & $11.5 \pm 3.6$ \\
\hline PaO2/FiO2,mmHg & $247.3 \pm 43.5$ \\
\hline PaCO2, mmHg & $40.2 \pm 5.7$ \\
\hline Cardiosurgery,n(\%) & $12(29.2)$ \\
\hline Preexisting COPD,n(\%) & $3(7.3)$ \\
\hline Septic shock,n(\%) & $15(36.6)$ \\
\hline ARDS,n(\%) & $11(26.8)$ \\
\hline ICU length of stay, days & $14.3 \pm 13.3$ \\
\hline Abbreviations: ARDS Acute respiratory distress syndrome, COPD Chronic Obstructive Pulmonary \\
\hline Disease.
\end{tabular}

\section{Effects of early mobilization on regional lung ventilation distribution}

The trend of ROI4 (dorsal region) significantly increased ( $p=0.01$ ) after early mobilization, but ROI 1-3 showed no significantly difference during study phases. Moreover, GI significantly decreased $(p=0.038)$ and COV significantly increased $(p=0.047)$ at $T_{60 \mathrm{~min}}$ compared to baseline (Fig. 1).

\section{Effects of early mobilization on respiratory and hemodynamic parameters}

As for respiratory parameters, a significant increase was observed in $\mathrm{SpO}_{2}(p=0.045)$ and $\mathrm{RR}(p=0.001)$. Besides, Heart rates has significantly increased after early mobilization $(p=0.011)$. But MAP remained stable over all study phases. (Table 2) 
Table 2

Changes of respiratory and hemodynamics parameters at different time points

\begin{tabular}{|c|c|c|c|c|c|c|}
\hline & $\mathrm{T}_{\text {base }}$ & $\mathrm{T}_{30 \min }$ & $\mathrm{T}_{60 \mathrm{~min}}$ & $\mathrm{~T}_{\text {return }}$ & Trend- $p$ & $\begin{array}{l}\text { Mauchly's test of } \\
\text { sphericity p value }\end{array}$ \\
\hline $\begin{array}{l}\text { HR, } \\
\text { beats/min }\end{array}$ & $85.5 \pm 11.6$ & $89.3 \pm 14.9$ & $90.2 \pm 14.6$ & $87.2 \pm 12.5$ & 0.011 & 0.021 \\
\hline $\begin{array}{l}\text { MAP, } \\
\mathrm{mmHg}\end{array}$ & $82.4 \pm 11.3$ & $82.4 \pm 11.9$ & $84.5 \pm 11.7$ & $84.0 \pm 12.0$ & 0.491 & 0.060 \\
\hline $\mathrm{SpO}_{2}, \%$ & $90.6 \pm 2.7$ & $91.8 \pm 1.9$ & $92.9 \pm 1.6$ & $91.0 \pm 2.3$ & 0.045 & 0.580 \\
\hline RR & $19.5 \pm 4.8$ & $22.3 \pm 5.2^{*}$ & $22.7 \pm 5.7^{\star}$ & $21.0 \pm 4.8$ & 0.001 & 0.027 \\
\hline \multirow{2}{*}{\multicolumn{7}{|c|}{$\begin{array}{l}\text { Abbreviations: } H R \text { Heart rate, } M A P \text { Mean arterial pressure, } S p O 2 \text { Peripheral oxygen saturation, } R F \\
\text { Respiratory rate } \\
\mathrm{T}_{\text {base }} \text { : supine position baseline, } \mathrm{T}_{30 \mathrm{~min}} \text { : sitting position for } 30 \mathrm{~min}, \mathrm{~T}_{60 \mathrm{~min}}: \text { sitting position for } \\
60 \mathrm{~min}, \mathrm{~T}_{\text {return }} \text { : return to supine position from sitting position }\end{array}$}} \\
\hline & & & & & & \\
\hline \multicolumn{7}{|c|}{$p$ value by General Linear Model Repeated Measures } \\
\hline \multicolumn{7}{|c|}{ Data are given as mean \pm SD } \\
\hline${ }^{\star} P \otimes 0.05$ & & & & & & \\
\hline
\end{tabular}

\section{Relationship between $\Delta \mathrm{ROI} 3+4$ and $\Delta \mathrm{SpO}_{2}, \mathrm{ROI} 4_{(\text {base })}$ and $\Delta \mathrm{ROI} 3+4$, ROI $4_{\text {(base) }}$ and $\Delta \mathrm{SpO}_{2}$}

Regarding the changes, we found that $\triangle \mathrm{ROI}(3+4)\left(\mathrm{ROI}(3+4)\right.$ at $\mathrm{T}_{60 \mathrm{~min}}-\mathrm{ROI}(3+4)$ at $\left.\mathrm{T}_{\text {base }}\right)$ and $\Delta \mathrm{SpO}_{2}\left(\mathrm{SpO}_{2}\right.$ at $\mathrm{T}_{60 \mathrm{~min}}-\mathrm{SpO}_{2}$ at $\left.\mathrm{T}_{\text {base }}\right)$ were positively related $\left(\mathrm{R}=0.71, p \otimes 0.001\right.$. Moreover, $\mathrm{ROI} 4_{\text {(base) }}\left(\mathrm{ROI} 4\right.$ at $\left.\mathrm{T}_{\text {base }}\right)$ was negatively related to $\Delta \mathrm{SpO}_{2}(\mathrm{R}=0.72, p \otimes 0.001$ and $\Delta \mathrm{ROI}(3+4)(\mathrm{R}=0.62, p=0.038)$.(Fig.2)

\section{Difference between DR and Non-DR groups}

18 patients could be categorized to the DR group, and 23 patients to the Non-DR group. Baseline characteristics of two groups are compared in Table 3. There were no significant differences in age, $\mathrm{PaO}_{2} / \mathrm{FiO}_{2}, \mathrm{HR}, \mathrm{RR}$ and days of ICU duration between these two groups at baseline.

Changes of respiratory and hemodynamic parameters in these two groups during study phases are shown in Table 4. There is a significant increase of $\mathrm{SpO}_{2}$ in $\mathrm{DR}$ group, while there is no significant 
difference in Non-DR group after early mobilization.

Table 3

Comparison baseline date in recruitment group (DR group) and not-recruitment group (Non-DR group).

\begin{tabular}{|c|c|c|c|}
\hline Variables & DR group & Non-DR group & $\mathrm{p}$ \\
\hline & $\mathrm{N}=18$ & $\mathrm{~N}=23$ & \\
\hline Age, years & $63.8 \pm 13.2$ & $64.5 \pm 14.3$ & 0.481 \\
\hline Male sex,n(\%) & 14(77.8) & 19(82.6) & 0.709 \\
\hline $\mathrm{BMI}, \mathrm{kg} / \mathrm{m}^{2}$ & $21.2 \pm 4.3$ & $22.0 \pm 3.8$ & 0.567 \\
\hline APACHE-II & $11.8 \pm 3.2$ & $11.2 \pm 4.5$ & 0.630 \\
\hline ICU length of stay, days & $15.3 \pm 4.2$ & $13.8 \pm 2.1$ & 0.345 \\
\hline $\mathrm{PaO}_{2} / \mathrm{FiO}_{2}, \mathrm{mmHg}$ & $233.5 \pm 45.1$ & $256.2 \pm 56.2$ & 0.162 \\
\hline $\mathrm{PaCO}_{2}, \mathrm{mmHg}$ & $39.8 \pm 7.2$ & $40.1 \pm 4.5$ & 0.515 \\
\hline ROI 1 & $14.2 \pm 11.6$ & $12.8 \pm 8.0$ & 0.833 \\
\hline ROI 2 & $43.0 \pm 11.7$ & $38.9 \pm 11.7$ & 0.212 \\
\hline ROI 3 & $36.9 \pm 11.7$ & $40.8 \pm 14.8$ & 0.408 \\
\hline ROI 4 & $5.9 \pm 4.0$ & $7.5 \pm 4.4$ & 0.043 \\
\hline $\mathrm{HR}$, beats/min & $83.2 \pm 8.4$ & $87.2 \pm 13.4$ & 0.124 \\
\hline MAP, mmHg & $80.8 \pm 11.3$ & $83.3 \pm 11.2$ & 0.782 \\
\hline RR & $19.7 \pm 4.1$ & $19.2 \pm 5.2$ & 0.620 \\
\hline $\begin{array}{l}\text { Abbreviations: } H R \text { Heart } \\
\text { Respiratory rate }\end{array}$ & arterial pres & Peripheral oxy & on, $R R$ \\
\hline$D R$ group:Dependent reg & up, Non-DR $\subseteq$ & endent region $n$ & group \\
\hline Data are given as mean & & & \\
\hline${ }^{*} P \otimes 0.05$ & & & \\
\hline
\end{tabular}


Table 4

Subgroup analysis of changes of respiratory and hemodynamics parameters at different time points

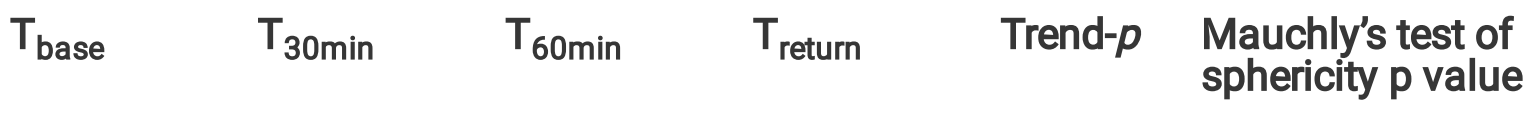

$\mathrm{SpO}_{2}, \%$

\begin{tabular}{lllllll} 
DR group & $90.8 \pm 3.1$ & $92.6 \pm 2.1$ & $93.2 \pm 1.3$ & $90.4 \pm 2.5$ & 0.035 & $\varangle 0.0001$ \\
$\begin{array}{l}\text { Non-DR } \\
\text { group }\end{array}$ & $92.1 \pm 2.3$ & $91.1 \pm 1.9$ & $92.2 \pm 1.3$ & $92.3 \pm 2.2$ & 0.567 & $\varangle 0.0001$ \\
\hline & & & & & &
\end{tabular}

MAP,

$\mathrm{mmHg}$

$\begin{array}{lllllll}\text { DR group } & 80.8 \pm 11.3 & 79.5 \pm 7.8 & 82.5 \pm 9.3 & 80.6 \pm 11.7 & 0.508 & 0.072\end{array}$

$\begin{array}{lllllll}\text { Non-DR } & 83.3 \pm 11.2 & 84.4 \pm 16.9 & 85.8 \pm 13.1 & 86.1 \pm 11.8 & 0.663 & 0.112\end{array}$

group

HR,

beats/min

$\begin{array}{lllllll}\text { DR group } & 83.2 \pm 8.4 & 83.7 \pm 8.1 & 84.3 \pm 8.2 & 82.7 \pm 7.6 & 0.342 & 0.017\end{array}$

$\begin{array}{lllllll}\begin{array}{l}\text { Non-DR } \\ \text { group }\end{array} & 87.2 \pm 13.4 & 90.4 \pm 17.3 & 94.6 \pm 16.7 & 90.6 \pm 14.2 & \square & 0.170 \\ \end{array}$

RR

\begin{tabular}{lllllll} 
DR group & $19.7 \pm 4.1$ & $21.4 \pm 4.6$ & $21.7 \pm 4.9$ & $21.1 \pm 4.8$ & 0.011 & 0.071 \\
$\begin{array}{l}\text { Non-DR } \\
\text { group }\end{array}$ & $19.2 \pm 5.2$ & $22.7 \pm 5.7$ & $23.2 \pm 6.3$ & $20.7 \pm 4.9$ & $\square$ & 0.386 \\
\hline & & & & & 0.0001 &
\end{tabular}

GI

\begin{tabular}{|lllllll|}
\hline DR group & $0.78 \pm 0.34$ & $0.79 \pm 0.36$ & $0.73 \pm 0.33$ & $0.74 \pm 0.24$ & 0.733 & 0.005 \\
\hline $\begin{array}{l}\text { Non-DR } \\
\text { group }\end{array}$ & $0.86 \pm 0.45$ & $0.78 \pm 0.30$ & $0.72 \pm 0.37$ & $0.95 \pm 0.76$ & 0.144 & 0.0001 \\
\hline
\end{tabular}

COV

\begin{tabular}{lllllll} 
DR group & $46.2 \pm 10.5$ & $50.4 \pm 11.0$ & $50.1 \pm 10.0$ & $48.2 \pm 10.7$ & 0.0001 & 0.441 \\
$\begin{array}{l}\text { Non-DR } \\
\text { group }\end{array}$ & $49.7 \pm 10.3$ & $49.7 \pm 9.1$ & $50.9 \pm 9.3$ & $50.5 \pm 13.0$ & 0.689 & 0.0001 \\
\hline
\end{tabular}

Abbreviations: $H R$ Heart rate, MAP Mean arterial pressure, SpO2 Peripheral oxygen saturation, $G \mathrm{I}$ Global inhomogeneity, COV Centre of ventilation. 
$T_{\text {base }}$ : supine position baseline, $T_{30 \mathrm{~min}}$ : sitting position for $30 \mathrm{~min}, \mathrm{~T}_{60 \mathrm{~min}}$ : sitting position for $60 \mathrm{~min}, \mathrm{~T}_{\text {return }}$ : return to supine position from sitting position

$p$ value by General Linear Model Repeated Measures

Data are given as mean \pm SD

${ }^{*} P \otimes 0.05$

\section{Using ROI 4(base) to distinguish DR patients}

If we use ROI 4 at baseline as a predictor to distinguish DR group from Non-DR group, ROC curve of ROI

$4_{\text {(base) }}$ diagnostic value was showed in Figure 3 . The best cut-off for $\mathrm{ROI} 4_{\text {(base) }}$ is $6.5 \%$, which means that in patients with an initial ROI 4 (base) $86.5 \%$,early mobilization may improve oxygenation and prefer to be performed. The specificity is $79.2 \%$, while the sensitivity only $58.8 \%$. Area under curve is $0.806(95 \% \mathrm{Cl}$, 0.677-0.936).

\section{Discussion}

In this study, we focused on body position change from supine to sitting on the wheelchair. We found that 1) early mobilization can induce lung recruitment in some but not all patients. 2) EIT is feasible in monitoring regional ventilation distribution change during early mobilization. 3) ROI $4_{\text {(base) }}$ was negatively related to $\Delta \mathrm{SpO}_{2}$ and lung recruitment in the dependent regions, which suggested that baseline ventilation distribution in the most dorsal regions might predict the recruitment responsiveness of early mobilization.

\section{Effects of early mobilization on lung recruitment}

As shown in previous study, early mobilization may introduce lung recruitment to prevent postoperative respiratory complications and increase ventilator-free days [6-8]. But controversial results were found in other studies $[9,10]$. In our study, early mobilization can induce lung recruitment in gravity-dependent lung area in some, but not in all patients, which explained the controversial results in previous studies.

Furthermore, we divided all patients into two types:(a) in DR group, patients showed recruitment in the dorsal region and better oxygenation after early mobilization. (b) in Non-DR group, patients didn't take advantage from early mobilization with no difference in oxygenation and recruitment. Thus, patients classified as type DR may have a greater potential for recruitment, which indicates that early mobilization therapy may benefit these patients and is recommended. Patients classified as type Non-DR may have limited potential for recruitment and should be used cautiously. 


\section{EIT on regional lung ventilation}

Early mobilization influences regional lung ventilation by body position changing. Previous researches have used EIT to monitor ventilation improvement during body position changing [23-27] and proved EIT's feasibility. Hough et al [24] confirmed that body position changes might influence regional ventilation distribution in infants, whereas Pauline S et al [25] reported no difference between lateral and supine positioning. Riedel et al [26] investigating supine and prone position by EIT and found ventilation in dependent lung region increased in the prone position.

In this study, we used EIT to monitor regional ventilation change from supine to sitting position. The results show that ROI4, CoV and GI improved in sitting position, which means more gas into dorsal region and ventilation became more homogenous. This result is in accord with previous study $[28,29]$. One study showed that FEV1 increased when healthy volunteers changed from supine to sitting position [28]. Another study found that sitting position constantly and significantly relieved expiratory flow limitation and auto-positive end-expiratory pressure resulting in a dramatic drop in alveolar pressures in critically ill obese patients under mechanical ventilation [29]. Due to the change of gravity direction and the shift of diaphragm, it was possible that EIT measurement included partially different lung tissue in supine and sitting positions. Nevertheless, the improvement from $T_{30 \mathrm{~min}}$ to $T_{60 \mathrm{~min}}$ confirmed the improvement of ventilation distribution in sitting position.

\section{ROI 4(base), SpO2 and lung recruitment}

A previous study showed that early mobilization could improve $\mathrm{SpO}_{2}$ [30], but may not be applicable to all of ICU patients. In the present study, we found $\mathrm{SpO}_{2}$ improvement in $78 \%$ patients in the DR group $(14 / 18)$ and only $26 \%$ patients have improved $\mathrm{SpO}_{2}$ in Non-DR group (6/23). In addition, we found that $\Delta \mathrm{SpO}_{2}$ and $\triangle \mathrm{ROI}(3+4)$ were positively related and $\mathrm{ROI} 4_{\text {(base) }}$ was negatively related to $\Delta \mathrm{SpO}_{2}$, which means patients with lower baseline ROI 4 proportion may have higher possibility to get lung recruitment and improved oxygenation after early mobilization. In clinical practice due to limited manpower, position change to sitting isn't easy to carry out for ICU patients. So it will be beneficial to distinguish specific group of patients who would benefit the most from early mobilization. The responsiveness to early mobilization could be partially predicted with $\mathrm{ROI} 4_{\text {base }}$ (Fig. 3 ).

\section{Limitations}

This study also has some limitations. First, we only monitored one-time of early mobilization for 1 hour and the study period may be not long enough to monitor regional ventilation changing. Second, the sample size might be considered not large enough for subgroup analysis. Third, during the 4 time points, patients need to be moved from supine position from bed to sitting position on wheelchair, although we had conducted it with cautious, the position of 16 -electrode belt of EIT might be still slightly shifted. So 
we did not compare the end expiration lung impedance level. Fourth, the threshold used to distinguish recruited and non-recruited groups (15\%) was arbitrary and its clinical value needs to be further studied.

\section{Conclusion}

Early mobilization can induce lung recruitment in dorsal lung regions and improve oxygenation in some but not all patients. The baseline ventilation distribution in the most dorsal regions might predict the recruitment responsiveness of early mobilization. EIT may be useful to identify patients who could benefit most from early mobilization.

\section{Declarations}

\section{Ethical Approval and Consent to participate}

The Institutional Research and Ethics Committee of the Peking Union Medical College Hospital approved this study on human subjects. Written informed consent was obtained from the patients' next of kin.

\section{Consent for publication}

All authors read and approved the final manuscript.

\section{Availability of data and materials}

Not applicable

\section{Conflicting interests}

Zhanqi Zhao receives consultant fee from Draeger Medical.

\section{Funding}

Capital's Funds for Health Improvement and Research (NO. 2020-2-40111) and Medical and health science and technology innovation project of Chinese Academy of Medical Sciences(NO. 2019-12M-1001)

\section{Authors' contributions}

SY and $\mathrm{HH}$ prepared the final copy of the manuscript and EIT-images. YC and SY performed the EIT examination and obtained patient's consent. HH, SY,YC, YL and ZZ drafting the manuscript for important 
intellectual content and interpretation for data.

\section{Acknowledgments}

Not applicable.

\section{Abbreviations}

EIT: electrical impedance tomography

$T_{\text {base }}$ : baseline, supine position at the bed

$T_{30 \mathrm{~min}}$ : sitting position on the wheelchair after $30 \mathrm{~min}$

$\mathrm{T}_{60 \mathrm{~min}}$ : sitting position on the wheelchair after $60 \mathrm{~min}$

$T_{\text {return }}$ : return to supine position on the bed after early mobilization

Gl: global inhomogeneity

CoV: center of ventilation

ROI: regions of interest

DR: Dependent region recruited group

Non-DR: Dependent region not-recruitment group

AUC: area under curve

PEEP: Positive End Expiratory Pressure

ARDS: acute respiratory distress syndrome

$\mathrm{PaO}_{2} / \mathrm{FiO}_{2}$ : Partial pressure of oxygen/Fraction of inspiration oxygen

$\mathrm{SpO}_{2}$ : oxygen saturation

RR: respiration rate

BMI: body mass index

HR: heart rate

MAP: mean arterial pressure 


\section{References}

1. Girard TD, Alhazzani W, Kress JP, Ouellette DR, Schmidt GA, Truwit JD, Burns SM, Epstein SK, Esteban A, Fan E, et al. An Official American Thoracic Society/American College of Chest Physicians Clinical Practice Guideline: Liberation from Mechanical Ventilation in Critically III Adults. Rehabilitation Protocols, Ventilator Liberation Protocols, and Cuff Leak Tests. Am J Respir Crit Care Med. 2017;195(1):120-33.

2. Wollersheim T, Grunow JJ, Carbon NM, Haas K, Malleike J, Ramme SF, Schneider J, Spies CD, Märdian S, Mai K, et al. Muscle wasting and function after muscle activation and early protocolbased physiotherapy: an explorative trial. Journal of cachexia sarcopenia muscle. 2019;10(4):73447.

3. Adamopoulos S, Corrà U, Laoutaris ID, Pistono M, Agostoni PG, Coats AJS, Crespo Leiro MG, Cornelis $J$, Davos $\mathrm{CH}$, Filippatos $\mathrm{G}$, et al. Exercise training in patients with ventricular assist devices: a review of the evidence and practical advice. A position paper from the Committee on Exercise Physiology and Training and the Committee of Advanced Heart Failure of the Heart Failure Association of the European Society of Cardiology. Eur J Heart Fail. 2019;21(1):3-13.

4. Schaller SJ, Anstey M, Blobner M, Edrich T, Grabitz SD, Gradwohl-Matis I, Heim M, Houle T, Kurth T, Latronico N, et al. Early, goal-directed mobilisation in the surgical intensive care unit: a randomised controlled trial. Lancet. 2016;388(10052):1377-88.

5. Truong AD, Fan E, Brower RG, Needham DM. Bench-to-bedside review: mobilizing patients in the intensive care unit-from pathophysiology to clinical trials. Crit Care (London England). 2009;13(4):216.

6. Cassidy MR, Rosenkranz P, McCabe K, Rosen JE, McAneny D. I COUGH: reducing postoperative pulmonary complications with a multidisciplinary patient care program. JAMA surgery. 2013;148(8):740-5.

7. Schweickert WD, Pohlman MC, Pohlman AS, Nigos C, Pawlik AJ, Esbrook CL, Spears L, Miller M, Franczyk M, Deprizio D, et al. Early physical and occupational therapy in mechanically ventilated, critically ill patients: a randomised controlled trial. Lancet. 2009;373(9678):1874-82.

8. Lunardi AC, Cecconello I, Carvalho CR: Postoperative chest physical therapy prevents respiratory complications in patients undergoing esophagectomy. Revista brasileira de fisioterapia (Sao Carlos (Sao Paulo, Brazil)) 2011, 15(2):160-165.

9. Tipping CJ, Harrold M, Holland A, Romero L, Nisbet T, Hodgson CL. The effects of active mobilisation and rehabilitation in ICU on mortality and function: a systematic review. Intensive care medicine. 2017;43(2):171-83.

10. Fossat G, Baudin F, Courtes L, Bobet S, Dupont A, Bretagnol A, Benzekri-Lefèvre D, Kamel T, Muller G, Bercault N, et al. Effect of In-Bed Leg Cycling and Electrical Stimulation of the Quadriceps on Global Muscle Strength in Critically III Adults: A Randomized Clinical Trial. Jama. 2018;320(4):368-78. 
11. Schweickert WD, Kress JP. Implementing early mobilization interventions in mechanically ventilated patients in the ICU. Chest. 2011;140(6):1612-7.

12. Albarrati A, Zafar H, Alghadir AH, Anwer S. Effect of Upright and Slouched Sitting Postures on the Respiratory Muscle Strength in Healthy Young Males. BioMed research international. 2018;2018:3058970.

13. Frerichs I, Hinz J, Herrmann P, Weisser G, Hahn G, Dudykevych T, Quintel M, Hellige G. Detection of local lung air content by electrical impedance tomography compared with electron beam CT. J Appl Physiol. 2002;93(2):660-6.

14. Bachmann MC, Morais C, Bugedo G, Bruhn A, Morales A, Borges JB, Costa E, Retamal J. Electrical impedance tomography in acute respiratory distress syndrome. Crit Care (London England). 2018;22(1):263.

15. Liu S, Tan L, Möller K, Frerichs I, Yu T, Liu L, Huang Y, Guo F, Xu J, Yang Y, et al. Identification of regional overdistension, recruitment and cyclic alveolar collapse with electrical impedance tomography in an experimental ARDS model. Crit Care (London England). 2016;20(1):119.

16. Franchineau G, Bréchot N, Lebreton G, Hekimian G, Nieszkowska A, Trouillet JL, Leprince P, Chastre J, Luyt CE, Combes A, et al. Bedside Contribution of Electrical Impedance Tomography to Setting Positive End-Expiratory Pressure for Extracorporeal Membrane Oxygenation-treated Patients with Severe Acute Respiratory Distress Syndrome. Am J Respir Crit Care Med. 2017;196(4):447-57.

17. Barber DC, Brown BH. Applied potential tomography. J Br Interplanet Soc. 1989;42(7):391-3.

18. Zhao Z, Steinmann D, Frerichs I, Guttmann J, Moller K. PEEP titration guided by ventilation homogeneity: a feasibility study using electrical impedance tomography. Crit Care (London England). 2010;14(1):R8.

19. Frerichs I, Hahn G, Golisch W, Kurpitz M, Burchardi H, Hellige G. Monitoring perioperative changes in distribution of pulmonary ventilation by functional electrical impedance tomography. Acta anaesthesiologica Scandinavica. 1998;42(6):721-6.

20. Spadaro S, Mauri T, Böhm SH, Scaramuzzo G, Turrini C, Waldmann AD, Ragazzi R, Pesenti A, Volta CA. Variation of poorly ventilated lung units (silent spaces) measured by electrical impedance tomography to dynamically assess recruitment. Crit Care (London England). 2018;22(1):26.

21. Frerichs I, Zhao Z, Becher T. Simple Electrical Impedance Tomography Measures for the Assessment of Ventilation Distribution. Am J Respir Crit Care Med. 2020;201(3):386-8.

22. Roy A. Estimating correlation coefficient between two variables with repeated observations using mixed effects model. Biometrical journal Biometrische Zeitschrift. 2006;48(2):286-301.

23. Bein T, Ploner F, Ritzka M, Pfeifer M, Schlitt HJ, Graf BM. No change in the regional distribution of tidal volume during lateral posture in mechanically ventilated patients assessed by electrical impedance tomography. Clin Physiol Funct Imaging. 2010;30(4):234-40.

24. Hough J, Trojman A, Schibler A. Effect of time and body position on ventilation in premature infants. Pediatr Res. 2016;80(4):499-504. 
25. van der Burg PS, de Jongh FH, Miedema M, Frerichs I, van Kaam AH. The effect of prolonged lateral positioning during routine care on regional lung volume changes in preterm infants. Pediatric pulmonology. 2016;51(3):280-5.

26. Ericsson E, Tesselaar E, Sjoberg F. Effect of Electrode Belt and Body Positions on Regional Pulmonary Ventilation- and Perfusion-Related Impedance Changes Measured by Electric Impedance Tomography. PloS one. 2016;11(6):e0155913.

27. Kotani T, Hanaoka M, Hirahara S, Yamanaka H, Teschner E, Shono A. Regional overdistension during prone positioning in a patient with acute respiratory failure who was ventilated with a low tidal volume: a case report. Journal of intensive care. 2018;6:18.

28. Naitoh S, Tomita K, Sakai K, Yamasaki A, Kawasaki Y, Shimizu E. The effect of body position on pulmonary function, chest wall motion, and discomfort in young healthy participants. $J$ Manipulative Physiol Ther. 2014;37(9):719-25.

29. Lemyze M, Mallat J, Duhamel A, Pepy F, Gasan G, Barrailler S, Vangrunderbeeck N, Tronchon L, Thevenin D. Effects of sitting position and applied positive end-expiratory pressure on respiratory mechanics of critically ill obese patients receiving mechanical ventilation*. Critical care medicine. 2013;41(11):2592-9.

30. Brasher PA, McClelland KH, Denehy L, Story I. Does removal of deep breathing exercises from a physiotherapy program including pre-operative education and early mobilisation after cardiac surgery alter patient outcomes? Aust J Physiother. 2003;49(3):165-73.

\section{Figures}



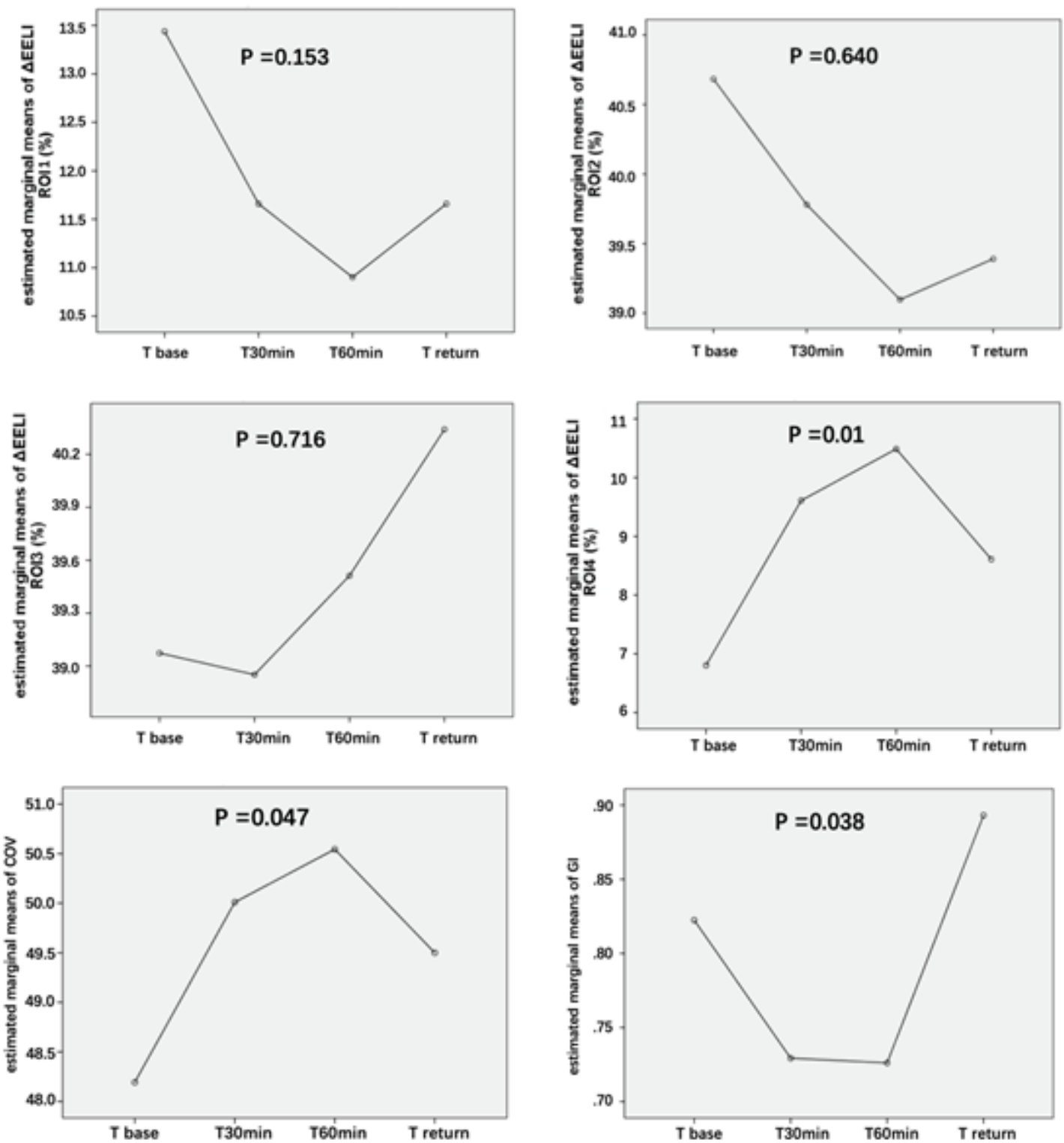

\section{Figure 1}

Evolution of estimated marginal means of ROI 1-4, GI and COV at different time points. $p$ value by General Linear Model Repeated Measures
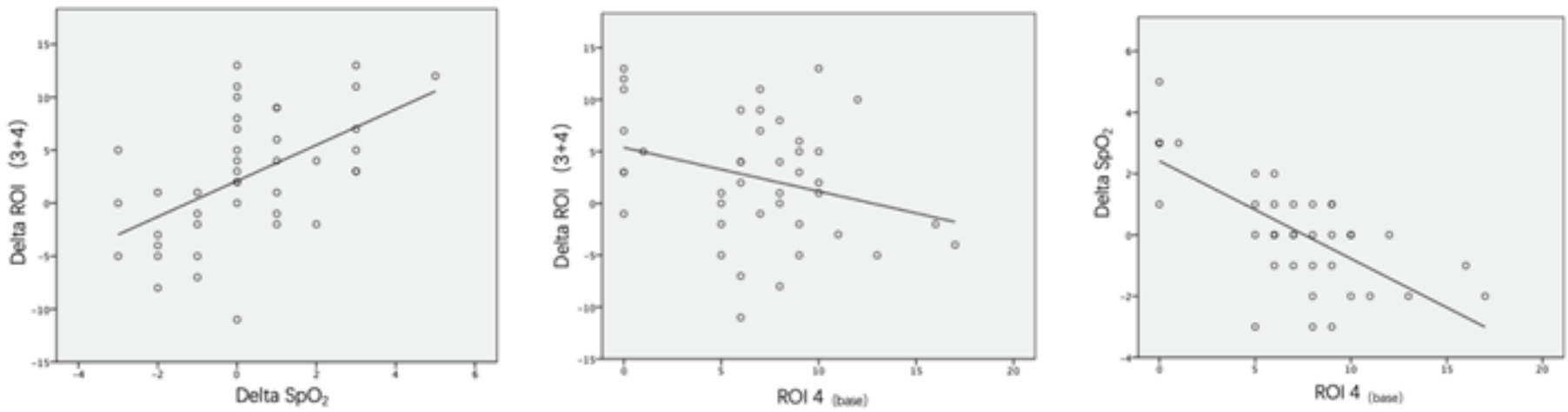

Figure 2 
Relationship between $\Delta \mathrm{ROI} 3+4$ and $\Delta \mathrm{SpO} 2, \mathrm{ROI} 4$ (base) and $\Delta \mathrm{ROI} 3+4, \mathrm{ROI} 4$ (base) and $\Delta \mathrm{SpO} 2$ in 41 patient. $\triangle \mathrm{ROI} 3+4$ means $\mathrm{ROI} 3+4$ at T60min- $\mathrm{ROI} 3+4$ at Tbase $\Delta$ SpO2 means SpO2 at T60min- SpO2 at Tbase ROI 4(base) means ROI 4 at Tbase Some data points overlap.

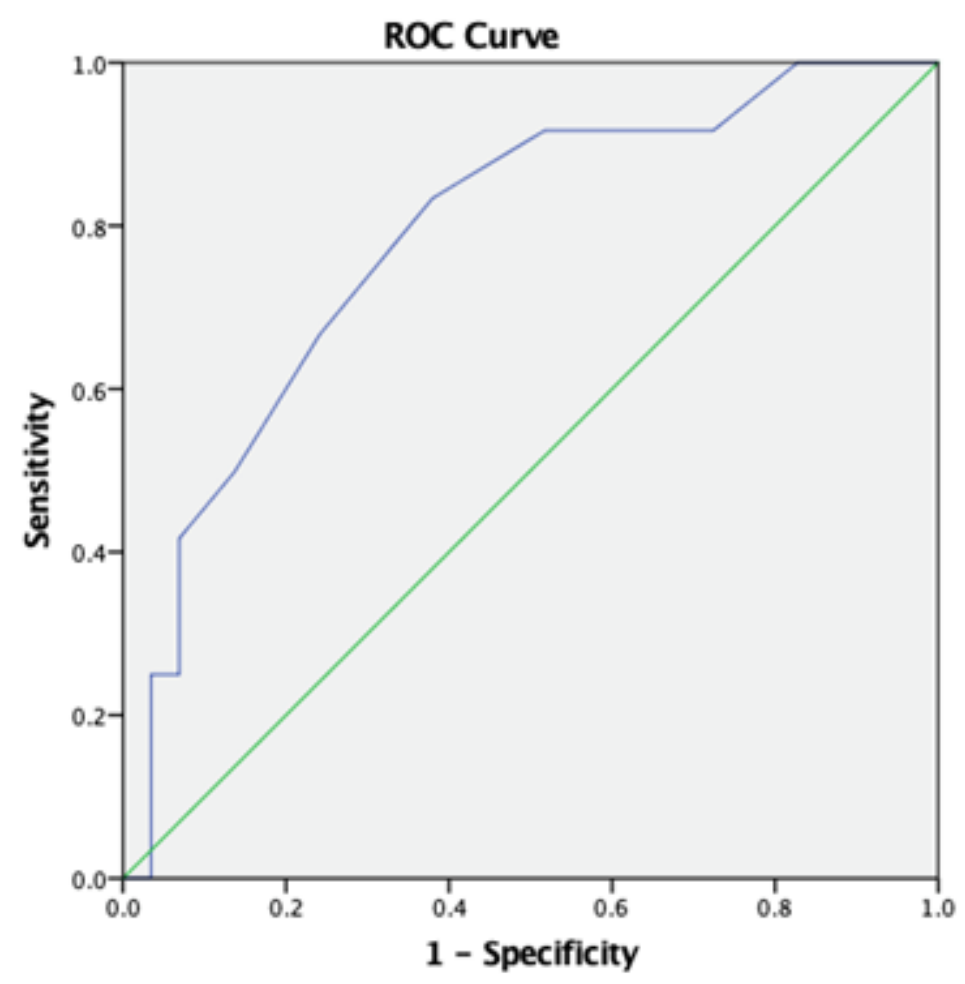

Figure 3

The ROC curve of using ROI 4(base) to distinguish DR patients(AUC 0.806 ) 